\title{
Priprava i karakterizacija poli(metil-metakrilatnih) kompozita s nanocelulozom
}

\author{
K. Mrkalj, F. Faraguna, E. Vidović i A. Jukić* \\ Fakultet kemijskog inženjerstva i tehnologije, Sveučilište u Zagrebu, \\ Trg Marka Marulića 19, 10000 Zagreb
}

\begin{abstract}
Sažetak
Ključne riječi

Poli(metil-metakrilat), nanoceluloza, DSC, SEC, priprava iz otopine
\end{abstract}

Provedenim istraživanjem priređeni su kompozitni materijali na osnovi poli(metil-metakrilata) i poli(metil-metakrilat-ko-dimetilaminoetil-metakrilata) s nanocelulozom u udjelu 1, 2,5 i 5 mas. \%. Metodom ex situ iz otopine dobivena je homogena raspodjela nanopunila u polimernoj matrici. Kromatografijom isključenja po veličini ustanovljeno je da jaka smična sila primijenjena pri homogenizaciji uzrokuje pucanje najvećih molekula polimera i time blago smanjenje prosjeka molekulskih masa polimerne matrice. Veća staklišta kompozita u odnosu na čiste polimerne matrice i porast staklišta s povećanjem udjela punila potvrđuju homogenost raspodjele i kompatiblnost nanoceluloze s istraživanim metakrilatnim matricama. Dodavanjem nanoceluloze povećava se hidrofilnost materijala, što olakšava tisak i može pogodovati njihovoj primjeni kao ambalažnih materijala.

\section{Uvod}

Zbog velike kristalne savršenosti, toplinske stabilnosti te poželjnih mehaničkih svojstava, nanoceluloza se istaknula kao potencijalno ojačavalo polimernih matrica. Nanoceluloza je općeniti termin koji se odnosi na nanostrukturiranu celulozu. Naspram same celuloze, posjeduje prednosti poput velike rastezne čvrstoće, visoke toplinske stabilnosti, velikog omjera duljine i promjera vlakna, razmjerno male gustoće $\left(1,6 \mathrm{~g} \mathrm{~cm}^{-3}\right)$ i velike specifične površine $\mathrm{s}$ hidroksilnim skupinama koje omogućavaju funkcionalizaciju karboksilacijom, esterifikacijom i drugim mehanizmima. ${ }^{1-4}$ Ovisno o polaznoj sirovini i željenoj primjeni može se dobiti u više različitih oblika. Proizvodi se iz sirovina kao što su drvo, biljke, alge, plaštenjaci ili bakterije i može se dobiti kroz više različitih procesa. Sukladno tome, ovisno o specifičnim svojstvima ili sirovini iz koje je dobivena pojam nanoceluloze može podrazumijevati celulozna nanovlakna, celulozne nanokristale ili bakterijsku nanocelulozu, koja se odnosi na nanostrukturiranu celulozu koju proizvode bakterije. lako su i celulozni nanokristali (CNK) i celulozna nanovlakna (CNV) nanoceluloza, između njih postoje bitne razlike. CNK-i (engl. cellulose nanocrystals, CNC, nanocrystalline cellulose, NCC, cellulose nanowhiskers, CNW) primarno sadrže kristalnu celulozu s vrlo malo amorfne celuloze ili hemiceluloze, dok CNV-i sadrže i amorfne i kristalne dijelove. CNK-i se uobičajeno javljaju u obliku kratkih, štapićastih čestica, dok su čestice CNV-a obično dulje (do nekoliko mikrometara, promjera oko $20 \mathrm{~nm}$ ), fleksibilnije $\mathrm{i}$ često razgranate ili rašljaste te formiraju strukturu sličnu mreži kakva je prikazana na slici 1 . CNK-i se tipično upotrebljavaju za primjene gdje je potrebna prozirnost, kao što su filmovi i barijere (ambalažni ma-

*Autor za dopisivanje: prof. dr. sc. Ante Jukić

E-pošta: ajukic@fkit.unizg.hr terijali), dok se CNV-i češće upotrebljavaju kao ojačavalo i modifikator viskoznosti. ${ }^{5,6}$

Zbog hidrofilnosti celuloze, CNV-i su kompatibilni samo s hidrofilnim matricama kao što su poli(vinil-alkohol) i poli(etilen-oksid). Da bi se spriječilo odvajanje faza odnosno poboljšala disperzija CNV-a u hidrofobnoj matrici, kao jedan od pristupa nameće se kemijska modifikacija površine CNV-a. Sakakibara i sur. ${ }^{7}$ esterifikacijom površine proizveli su dobro dispergiran kompozit s 10 mas. \% udjelom CNV-a u HDPE matrici. Drugi pristup podrazumijeva upotrebu površinski aktivne tvari koja se adsorbira na površinu CNV-a molekulskim međudjelovanjima. Huex $i$ sur. ${ }^{8}$ modificirali su površinu celuloznih nanovlakana neionskim niskomolekularnim tenzidom. Međutim, mane tog pristupa su postojanje slobodnih molekula tenzida u sustavu, niska adsorpcijska/desorpcijska konstanta, visoka kritična koncentracija micela i slabo steričko odbijanje između CNV-a. Naime, micele u polimeru djeluju kao plastifikatori ili omekšavala i time mijenjaju mehanička svojstva novonastalog materijala, dok slabo steričko odbijanje uzrokuje agregaciju CNV-a. Sakakibara i sur. ${ }^{7}$ upotrijebili su dibločni kopolimer poli[(lauril-metakrilat)-ko-hidroksietil-metakrilat], gdje je blok jednog monomera većeg afiniteta za CNV, a blok drugog monomera većeg afiniteta za polimernu matricu. Kopolimer sprječava međusobno vezanje CNV-a vodikovim vezama tako što površinu $\mathrm{CNV}$-a čini praktično hidrofobnom.

Celulozni nanokristali, CNK-i (CNC, NCC, CNW) proizvode se iz prirodnih vlakana, uglavnom hidrolizom pomoću kiseline iz drvne pulpe kao polazne sirovine, čime nastaju krute štapićaste nanočestice visoke kristalnosti, kraće nego CNV-i koji su uobičajeno dobiveni mljevenjem. Promjera su od približno $5 \mathrm{~nm}$ i duljine od oko $150-200 \mathrm{~nm}$. Veći kristali mogu se proizvesti iz pamuka $(10-500 \mathrm{~nm})$ ili algi $(20-1000 \mathrm{~nm}) .^{9}$ 

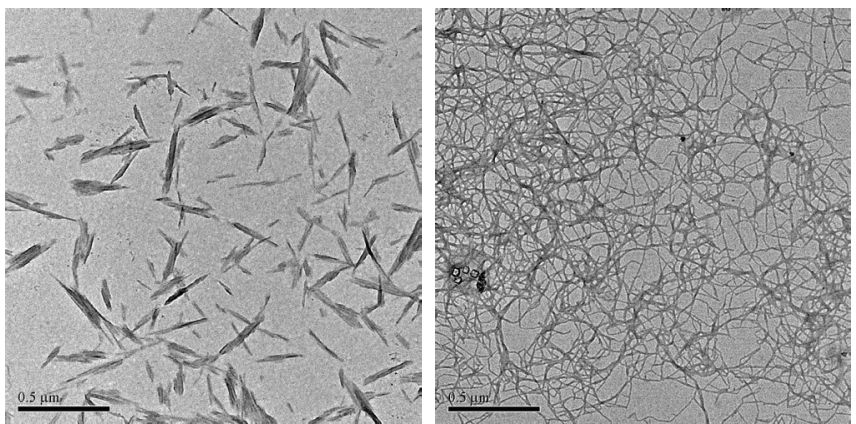

Slika 1 - TEM mikrografija CNK-a (lijevo) i CNV-a (desno $)^{10}$ Fig. 1 - TEM micrography of CNC (left) and CNV (right) ${ }^{10}$

U skladu s današnjom usmjerenošću prema primjeni nanotehnologije i zaštiti okoliša, velika se pozornost posvećuje uporabi obnovljivih, bioloških nanomaterijala. Shodno tome, vlada velik interes znanstvene zajednice za nanocelulozom. Razvitak i primjena polimernih kompozitnih materijala ojačanih nanočesticama i nanovlaknima privlačni su kako sa znanstvenog tako i s industrijskog stajališta. Polimerni kompoziti ojačani nanocelulozom mogu biti proizvedeni dodatkom CNV-a i CNK-a i poslužiti u proizvodnji ploča, filmova, folija (vreća za smeće, vreća za namirnice), ambalažnih materijala, proizvoda od papira i kartona, konstrukcijskih i građevnih materijala i drugih. Jedni od prvih koji su pojasnili učinak ojačanja kod nanoceluloznih kompozita pri malim udjelima nanoceluloze su Favier i sur. ${ }^{11,12}$ Oni su upotrijebili nanocelulozne viskere proizvedene iz plaštenjaka i njima ojačali lateks stiren-butilakrilatnog kopolimera s udjelom ojačavala do 6 mas. \%. Pokazalo se da i pri tim malim udjelima kompoziti posjeduju znatno bolja mehanička svojstva od polaznog polimera, što su autori pripisali stvaranju krute mreže celuloznih vlakana. Kasnije su Dufresne $i$ Vignon $^{13}$ pokazali da su CNV-i poboljšali i mehanička svojstva škrobne matrice. Dodatno, Nakagaito i Yano ${ }^{14}$ pokazali su da CNV-i također poboljšavaju rasteznu čvrstoću fenol-formaldehidne smole, a Zimmermann $i$ sur. ${ }^{15}$ da dodatak CNV-a poboljšava svojstva hidroksipropilirane celuloze. Fujisawa $i$ sur. ${ }^{16}$ pripremili su disperziju CNV-a te je miješali s otopinom PMMA u dimetilformamidu u različitim udjelima. Mješavina je izlivena u zdjelice i sušena $24 \mathrm{~h}$ pri $70{ }^{\circ} \mathrm{C}$ nakon čega je slijedilo vakuumsko sušenje na $70{ }^{\circ} \mathrm{C}$ tjedan dana. Dobiveni su filmovi čija je debljina bila oko $90 \mu \mathrm{m}$. Volumni udio CNV-a u filmovima kretao se između 0,1 i $25 \%$. Pripremljeni nanokompoziti PMMA imali su veliku prozirnost čak $i$ uz vrlo velik udio CNV-a od 25 vol. \%. TEM mikrografije presjeka pokazale su da su CNV-i homogeno raspodijeljeni te formiraju mrežu vlakana u PMMA matrici. Mjerenja su pokazala porast staklišta, što je pripisano otežanom gibanju glavnog PMMA lanca. Naime, segmentna gibanja ograničena su zbog privlačnih sila karbonilnog dijela lanca PMMA i polarnih skupina na površini CNV-a. Pretpostavljeno je i da se na međupovršini PMMA-CNV javljaju vodikove veze.

Uzevši u obzir potencijal koji CNV-i imaju kao ojačavalo i samu dostupnost celuloze, polimerni kompoziti ojačani nanocelulozom nameću se kao izvrstan odabir za primjene u kojima su važni mehanička svojstva i prozirnost. Dobra termomehanička svojstva koja ti kompoziti imaju posljedica su snažnih i krutih mreža koje formiraju vlakna uslijed čega dolazi do povećanja krutosti i rastezne čvrstoće kompozita. ${ }^{16}$ Upotreba polimera topljivih u vodi kao što je poli(vinil-alkohol), PVA, pomaže disperziju CNV-a unutar matrice. Naime, PVA je vodotopljivi termoplast s potencijalom stvaranja kvalitetnih filmova, lako se prerađuje i ima visoku rasteznu čvrstoću i fleksibilnost. Iz tih razloga zanimljiv je kao potencijalna matrica za polimerne kompozite s nanocelulozom. $U$ jednom od radova, Cho i Park ${ }^{17}$ izlili su suspenziju CNK nanoceluloze i PVA na Petrijevu zdjelicu. Rezultati su pokazali da se rastezni modul elastičnosti proizvedenog filma smanjio u odnosu na polazni polimer uz dodatak 1 mas. \% CNK, no zatim povećavao s povećanjem udjela nanoceluloze sve do $5 \%$, nakon čega je ponovno uslijedio pad. Neovisno su i Bulota i sur. ${ }^{18}$ pripremili nanokompozitni film CNV i PVA pri različitim masenim udjelima CNV-a. Slično kao i kod njihovih prethodnika, rezultati su pokazali da je najveći modul dobiven pri udjelima nanoceluloze od 4 do 5 mas. \%. Kao matrice upotrijebljeni su i drugi polimeri, pa su tako u istraživanju Menezesa $i$ sur. ${ }^{19}$ za ojačanje polietilena niske gustoće (LDPE) upotrijebljeni funkcionalizirani CNK-i cijepljeni s kloridima organskih kiselina. Kompozit na osnovi matrice celuloznog acetobutirata s disperznom fazom od nefunkcionaliziranih i trimetilsiliranih CNK-a koji su omogućili bolju adheziju između dviju faza opisali su Grunert i Winter. ${ }^{20}$

U ovom radu istraženi su i opisani priprava i neka osnovna strukturna i toplinska svojstva kompozitnih materijala na osnovi poli(metil-metakrilata) i kopolimera metil-metakrilata (MMA) s dimetilaminoetil-metakrilatom (DMAEMA), s celuloznim nanokristalima u udjelu do 5 mas. \%. DMAEMA je dodan da bi se ustanovio utjecaj povećanja polarnosti polimerne matrice na dispergiranost nanopunila i svojstva kompozita.

\section{Eksperimentalni dio}

\subsection{Sinteza polimera i priprema nanokompozita}

Za sintezu poli(metil-metakrilata) (PMMA) i poli(metil-metakrilat-ko-dimetilaminoetil-metakrilata) (PM9D1) upotrijebljeni su metil-metakrilat (99\%, Sigma Aldrich) i dimetilaminoetil-metakrilat (98\%, Sigma Aldrich) kao monomeri, tert-butil peroksi-2-ethilheksanoat (Trigonox $21^{\circledR}$, Akzo Chemie, $70 \%$ otopina u ulju) kao inicijator te toluen (p.a., Carlo Erba Reagenti) kao otapalo. Prilikom pripreme nanokompozita kao punilo upotrijebljena je nanoceluloza (Nanografi) prosječne dimenzije čestica $10-20 \mathrm{~nm} \times 300-900 \mathrm{~nm}$, kristalnosti $92 \%$ (XRD), gustoće $1,49 \mathrm{~g} \mathrm{~cm}^{-3}$ te s udjelom vode do 4 mas. \%. Kloroform (Lach-Ner) je upotrijebljen kao otapalo za pripremu nanokompozita.

PMMA je sintetiziran radikalskom polimerizacijom u otopini toluena ( $w=50$ mas. \%). Prilikom sinteze upotrijebljen je monofunkcionalni inicijator koji je dodavan u tri obroka u razmacima od pola sata. Ukupna reakcija vođena je $4 \mathrm{~h}$ u kotlastom reaktoru pri temperaturi od $95{ }^{\circ} \mathrm{C}$. Po završetku reakcije reakcijska smjesa ispušta se u teflonski kalup te se otapalo uklanja sušenjem pod vakuumom pri 
temperaturi od $120^{\circ} \mathrm{C}$ do konstantne mase. Za sintezu kopolimera PM9D1 primijenjen je isti postupak, samo je za reakcijsku smjesu pripremljena smjesa monomera koja je sadržavala 90 mol. \% metil-metakrilata (MMA) i 10 mol. \% dimetilaminoetil-metakrilata (DMAEMA). Sintetizirani polimeri zatim su otopljeni u kloroformu te je dobivena 40 mas. \% otopina. U navedenu otopinu dodano je 1, 2,5 ili 5 mas. \% nanoceluloze te je smjesa homogenizirana $120 \mathrm{~s}$ pri $10000 \mathrm{~min}^{-1}$ pomoću mehaničkog homogenizatora. Homogenizirana smjesa izlivena je u tankom sloju u teflonske kalupe i brzo je uklonjeno otapalo (oko 90 mas. \% otapala unutar 5 min) u vakuumskom sušioniku pri $80{ }^{\circ} \mathrm{C}$. Nanokompozit je sušen do konstantne mase. Osušeni nanokompoziti usitnjeni su lomljenjem, prešani pri $180{ }^{\circ} \mathrm{C}$ (predgrijavanje $3 \mathrm{~min}$, prešanje $5 \mathrm{~min}$ pri $10 \mathrm{MPa}$ ) te su dobiveni finalni uzorci, koji su analizirani.

\subsection{Analiza polimera i nanokompozita}

Određivanje raspodjele molekulskih masa i pripadajućih prosjeka molekulskih masa te disperznosti desintetiziranih polimera provedeno je kromatografijom isključenja po veličini (SEC). Mjerenja su provedena na kromatografskom uređaju PL-GPC 20 Polymer Laboratories, opremljenom refraktometrijskim osjetilom (RI). Razdjelnu jedinicu čine dvije serijski povezane PLgel Mixed-B kolone ispunjene polistiren-divinilbenzen kopolimernim gelom veličine čestica $3-100 \mu \mathrm{m}$. Brzina protjecanja tetrahidrofurana, koji je služio i kao otapalo i kao eluens, kroz kromatografski sustav bila je $1 \mathrm{~cm}^{3} \mathrm{~min}^{-1}$. Mjerenja su provedena pri sobnoj temperaturi, a za preračunavanje vremena zadržavanja (volumena eluiranja) u molekulsku masu primijenjene su specifične baždarne krivulje za polistiren (EasyCal PS-1B, 580-2560000 $\mathrm{g} \mathrm{mol}^{-1}$ ). Uzorci su pripravljeni otapanjem 70 - 80 mg uzorka u tetrahidrofuranu (čistoće p.a.), pri čemu je maseni omjer uzorka prema otapalu bio 1 : 75 . Kod nanokompozita čestice nanoceluloze uklonjene su taloženjem u razrijeđenoj otopini, pri čemu se sva nanoceluloza razdvojila od polimerne matrice te je analizirana samo polimerna matrica. Skenirajućom elektronskom mikroskopijom (SEM) snimljeni su krti presjeci uzoraka na VEGA 3 TESCAN mikroskopu s detektorom sekundarnih elektrona. Svi uzorci su prije analize napareni s vodljivim slojem (Au/Pd) da bi se poboljšala njihova vodljivost. Termogravimetrijskom analizom (TGA) praćen je utjecaj udjela nanoceluloze i priprave na toplinsku postojanost materijala praćenjem promjene mase s povećanjem temperature brzinom zagrijavanja od $10{ }^{\circ} \mathrm{C}$ u minuti u atmosferi dušika do $600{ }^{\circ} \mathrm{C}$ (uređaj TA TGA Q500). Pretražnom razlikovnom kalorimetrijom (DSC) praćeni su toplinski prijelazi pomoću uređaja DSC823e Mettler Toledo. Ispitivanja su provedena u inertnoj struji dušika te su snimana dva ciklusa grijanja i hlađenja (od $25^{\circ} \mathrm{C}$ do $160{ }^{\circ} \mathrm{C}$ ) pri brzini promjene temperature od $10{ }^{\circ} \mathrm{C}$ u minuti. $U$ rezultatima će se razmatrati rezultati dobiveni iz drugog ciklusa zagrijavanja jer se prvim zagrijavanjem uklonio utjecaj povijesti prethodne obrade uzorka (naprezanja zaostala prilikom pripreme i prešanja uzorka). Kontaktni kut vode na površini polimera i nanokompozita mjeren je uređajem OCAH 200 Data Physics Contact Angle System kapanjem 2 ul vode na površinu uzorka pri sobnoj temperaturi.

\section{Rezultati i rasprava}

\subsection{Utjecaj priprave nanokompozita na molekulsku masu polimerne matrice}

Molekulska masa temeljno je svojstvo sintetskih polimera i u velikoj mjeri određuje njihova glavna svojstva. Nanokompoziti su pripremljeni metodom ex situ, pri čemu je homogenizacija provedena mehanički uz velike smične brzine koje mogu uzrokovati pucanje kemijskih veza u polimernim molekulama (uobičajeno pri sredini lanca) i time znatno smanjenje prosjeka molekulskih masa. ${ }^{21,22}$ Dodatno, nakon priprave ex situ uzorci nanokompozita prešani su pri povišenoj temperaturi da bi se simulirao postupak prerade i dobivanja otpresaka (izradaka), odnosno pločica za daljnju analizu. Na taj način procjenjuje se mogućnost primjene pripravljenih kompozita na većoj, industrijskoj skali. ${ }^{23}$ Tom prilikom polimer je bio izvrgnut razmjerno visokoj temperaturi, što je moglo uzrokovati toplinsku degradaciju polimerne matrice. ${ }^{22}$ Stoga su izmjerene krivulje raspodjele molekulskih masa za PMMA homopolimer prije i nakon pripreme nanokompozita s različitim udjelima punila, da bi se utvrdio utjecaj načina priprave i udjela nanoceluloze na prosjeke molekulskih masa. Parametri raspodjele masa dani su u tablici 1, a na slici 2 prikazane su pripadajuće integralne i diferencijalne krivulje raspodjele izračunate iz izmjerenih kromatograma.

Tablica 1 - Brojčani $\left(M_{n}\right)$, maseni $\left(M_{w}\right)$ i z-prosjek $\left(M_{z}\right)$ molekulskih masa te disperznost (Đ) PMMA polimerne matrice prije i nakon priprave ex situ nanokompozita s 1 , 2,5 i 5 mas. \% udjelom nanoceluloze

Table 1 - Number $\left(M_{n}\right)$, mass $\left(M_{w}\right)$ and z-average $\left(M_{z}\right)$ molecular weights as well as dispersion ( $Đ$ ) of PMMA polymer matrix before and after ex situ preparation of nanocomposites with $1,2.5$, and 5 wt. \% nanocellulose share

\begin{tabular}{l|c|c|c|c}
\hline Uzorak & $M_{\mathrm{n}} / \mathrm{kg} \mathrm{mol}^{-1}$ & $M_{\mathrm{w}} / \mathrm{kg} \mathrm{mol}^{-1}$ & $\mathrm{M}_{\mathrm{z}} / \mathrm{kg} \mathrm{mol}^{-1}$ & $Ð /-$ \\
\hline PMMA* & 43 & 101 & 206 & 2,35 \\
\hline PMMA-C0 & 44 & 96 & 180 & 2,15 \\
\hline PMMA-C1 & 40 & 88 & 165 & 2,19 \\
\hline PMMA-C2,5 & 43 & 90 & 159 & 2,07 \\
\hline PMMA-C5 & 46 & 95 & 174 & 2,05 \\
\hline
\end{tabular}

* PMMA - polimer prije mehaničke i toplinske obrade

* PMMA - polymer before mechanical and thermal treatment

Uspoređujući prosjeke molekulskih masa čiste PMMA polimerne matrice prije i nakon mehaničke i toplinske obrade, vidljivo je njihovo blago smanjenje, osobito za maseni i z-prosjek, gdje su vrijednosti niže za oko $5 \%$. U isto vrijeme smanjuje se i disperznost jer rezultira uža raspodjela molekulskih masa. Kao što se može vidjeti i iz prikazanih krivulja raspodjele (slika 2), najmanja je smična i toplinska postojanost najvećih makromolekula. Njihovim pucanjem nastaju manje molekule koje su unutar postojeće raspodjele masa, pa se time dobivaju nešto uža raspodjela i niža disperznost. Slične su pojave zabilježene i pri istraživanju utjecaja velikih smičnih naprezanja na molekulske mase polimernih aditiva mazivih ulja gdje su pojave 


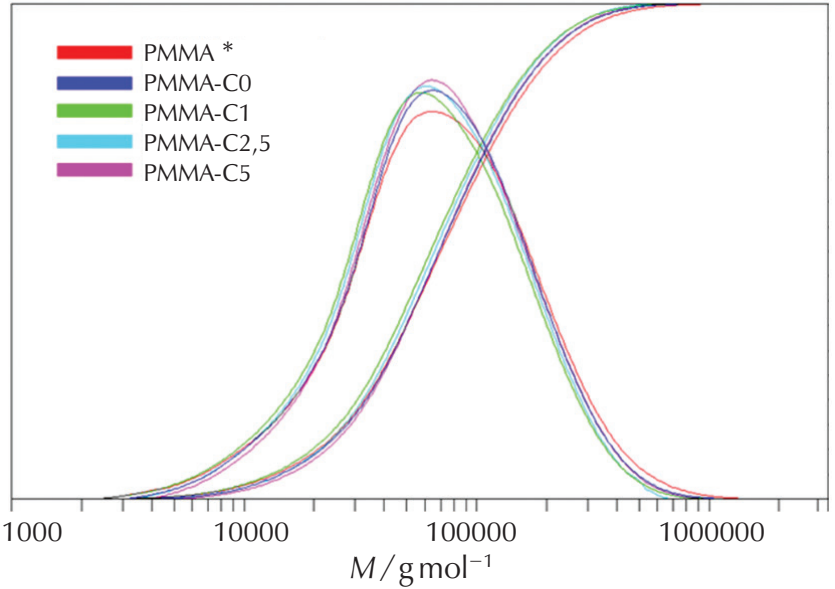

Slika 2 - Raspodjela molekulskih masa određena SEC kromatografijom za PMMA matrice prije i nakon priprave ex situ kompozita s $0,1,2,5$ i 5 mas. \% nanoceluloze (*PMMA - polimer prije mehaničke i toplinske obrade)

Fig. 2 -Molecular weight distribution determined by SEC chromatography for PMMA matrix before and after processing for prepration of nanocomposites with $0,1,2.5$, and 5 wt. \% nanocellulose (*PMMA - polymer before mechanical and thermal treatment)

degradacije uslijed duljeg izlaganja naprezanjima i znatno više izražene. ${ }^{24}$ Dodatkom nanoceluloze $u$ udjelima od $1 \mathrm{i}$ 2,5 mas. \% smanjenje prosjeka molekulskih masa je nešto veće u odnosu na čisti PMMA, do $13 \%$ za $M_{\mathrm{w}}$. Disperznost polimera također se dodatno smanjuje. S obzirom na sličnost temeljnog lanca, isto vjerojatno vrijedi i za kopolimernu matricu MMA i DMAEMA. Ukupno gledano, može se zaključiti da dodatak nanoceluloze i primijenjeni postupak priprave imaju razmjerno blag utjecaj na degradaciju polimerne matrice. Dakle, promjena svojstava, koju pokazuju rezultati preostalih mjerenja, uzrokovana je većim dijelom dodatkom nanoceluloze, a manje degradacijom polimerne matrice.

\subsection{Analiza raspodjele punila kroz polimernu matricu}

Za prijenos izvanrednih svojstava nanopunila na više razine potrebno je osigurati njegovu izvrsnu raspodijeljenost u matrici, koja, također, mora biti zadržana i tijekom postupaka prerade, inače takvi nanokompoziti nemaju uporabnu vrijednost. ${ }^{23}$ Analiza raspodjele nanoceluloze u PMMA matrici praćena je skenirajućom elektronskom mikroskopijom, pri čemu su analizirani presjeci nakon krtog loma uzorka (slika 3). Pretraživanjem lomne površine nisu pronađeni aglomerati nanoceluloze, što se može protumačiti dvojako: a) nakon loma svi aglomerati su zbog loše adhezije s matricom ispali s lomne površine te ih nije moguće uočiti na mikroskopu; b) adhezija nanoceluloze i polimerne matrice je dobra te je došlo do njezine homogene raspodjele kroz masu materijala. $U$ korist drugoj mogućnosti govori činjenica da je pretraživanjem većeg broja uzoraka (15-ak lomnih površina) pronađena tek jedna nakupina nanoceluloze, to jest jedna čestica mikroceluloze (slika 3) i
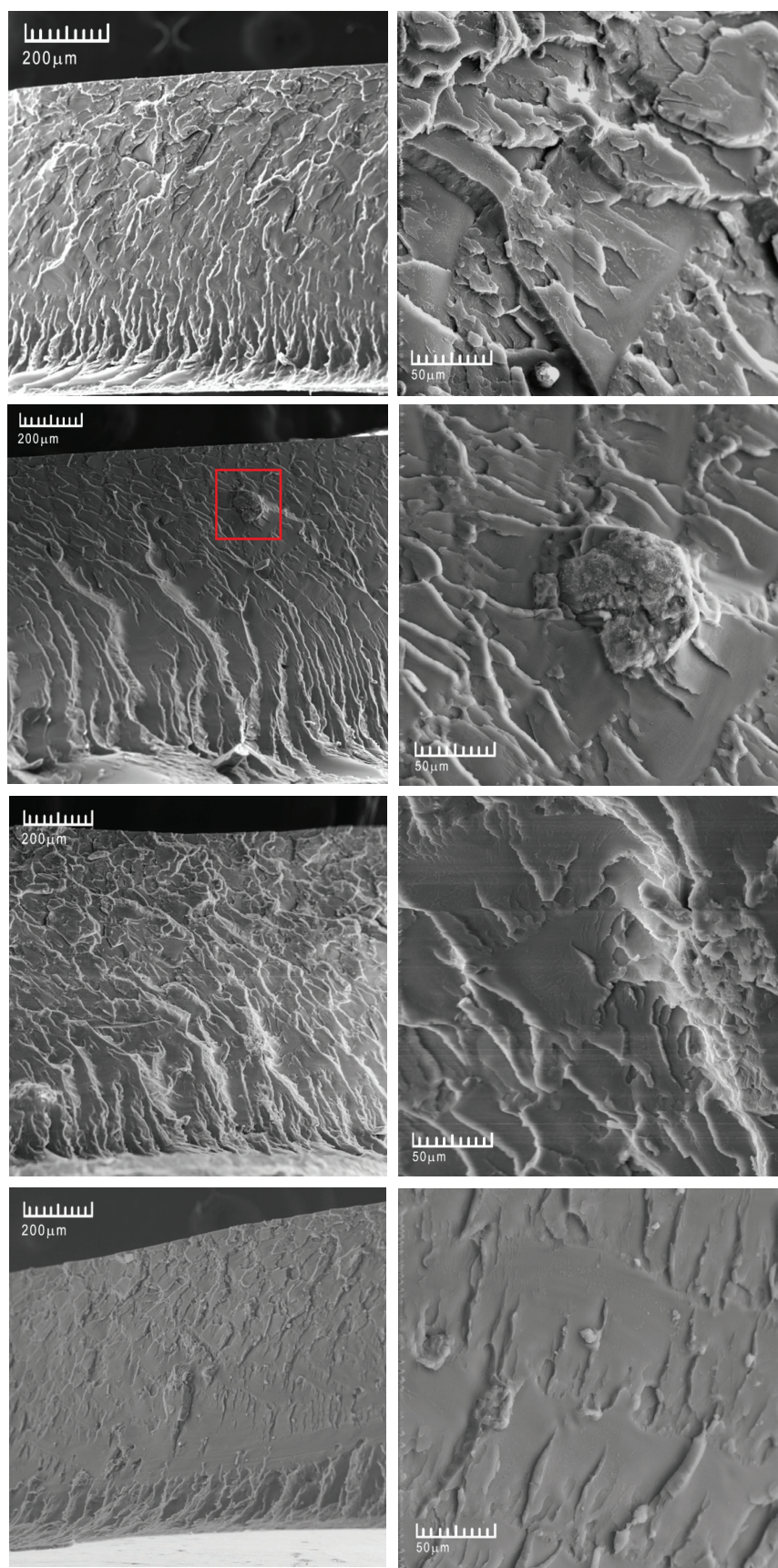

Slika 3 - SEM mikrografije lomnog presjeka PMMA: (1. red) na uvećanjima od 221 (lijevo) i 1320 puta (desno); nanokompozit PMMA-C1 (2. red) s uočenim aglomeratom nanoceluloze na uvećanjima od 254 (lijevo) i 1140 puta (desno); nanokompozit PMMA-C2,5 na uvećanjima od 257 (lijevo) i 1260 puta (desno); nanokompozit PMMA-C5 na uvećanjima od 254 (lijevo) i 1310 puta (desno).

Fig. 3 - SEM micrographs of brittle fracture of PMMA: (1 ${ }^{\text {st }}$ row) at magnifications of 221 (left) and 1320 times (right); nanocomposite PMMA-C1 ( $2^{\text {nd }}$ row) with observed nanocellulose agglomerate at magnifications of 254 (left) and 1140 times (right); nanocomposite PMMA-C2.5 at magnifications of 257 (left) and 1260 times (right); nanocomposite PMMA-C5 at magnifications of 254 (left) and 1310 times (right). 
nisu nađeni površinski defekti koji bi ukazivali na ispadanje nakupina punila iz polimerne matrice. Pretpostavka je da se radi o mikročestici prisutnoj u nanopunilu i prije priprave kompozita. Budući da je to jedina nađena nakupina, pretpostavlja se da je sva preostala nanoceluloza neaglomerirana i homogeno raspodijeljena kroz uzorak.

\subsection{Utjecaj udjela punila na svojstva nanokompozita}

Priređeni materijali ispitani su razlikovnom pretražnom kalorimetrijom (DSC) koja je omogućila praćenje utjecaja dodanog celuloznog nanopunila na temperature staklastog prijelaza polimernih matrica (slika 4). Utjecaj nanoceluloze na gibljivost polimernih lanaca iskazuje se time da dodatkom 1 mas. \% nanoceluloze u PMMA matricu staklište raste od $91,7{ }^{\circ} \mathrm{C}$ na $98,4{ }^{\circ} \mathrm{C}$, a daljnjim dodatkom nanoceluloze staklište poraste na 102,4 (2,5 mas. \%) i 112,9 (5 mas. \%). Porast temperature staklastog prijelaza ukazuje na to da prisutnost nanoceluloze smanjuje gibljivost segmenata polimernih lanaca te je potrebno više energije da se oni pokrenu. Tome su dva glavna razloga: interakcije između nanoceluloze i PMMA lanaca te steričko ograničavanje gibljivosti PMMA lanaca. ${ }^{25,26}$
Dodatak dimetilaminoetil-metakrilatne komonomerne jedinice u polimerni lanac povećao je njegovu gibljivost te snizio staklište za $10{ }^{\circ} \mathrm{C}$. Navedeno sniženje je očekivano, jer izmjereno staklište poli(dimetilaminoetil-metakrilat) homopolimera iznosi $20,0{ }^{\circ} \mathrm{C}$. Dodatak nanoceluloze u PM9D1 kopolimernu matricu pokazuje sličan utjecaj kao i kod PMMA matrice. Staklište se s vrijednosti $82,0{ }^{\circ} \mathrm{C}$ zabilježene za čisti kopolimer, pomiče na $87,8{ }^{\circ} \mathrm{C}$ (1 mas. \%), $93,6{ }^{\circ} \mathrm{C}\left(2,5\right.$ mas. \%) i $104,6{ }^{\circ} \mathrm{C}$ (5 mas. \%) za kompozite. Takav jasan rastući trend temperatura staklastog prijelaza s povećanjem udjela punila u nanokompozitu potvrđuje pretpostavku o homogenoj raspodijeljenost nanoceluloze u obje polimerne matrice. ${ }^{27}$

Toplinska stabilnost priređenih materijala ispitana je termogravimetrijskom analizom. Nanokompozitni uzorci na osnovi PMMA toplinski se raspadaju u tri koraka: prvi u području od 170 do $230{ }^{\circ} \mathrm{C}$, drugi u području od 250 do $350{ }^{\circ} \mathrm{C}$ te treći od 350 do $460{ }^{\circ} \mathrm{C}$ (slika 5). U literaturi ${ }^{28}$ su istražena navedena tri koraka te je poznato da pri najnižim temperaturama pucaju veze glava-glava i rep-rep zbog steričkih naprezanja i induktivnog učinka vicinalnih eterskih grupa. Drugi korak vezan je uz depolimerizaciju nezasićenih komonomera na krajevima lanca koji su nastali zbog terminacije disproprcioniranjem. Treći korak
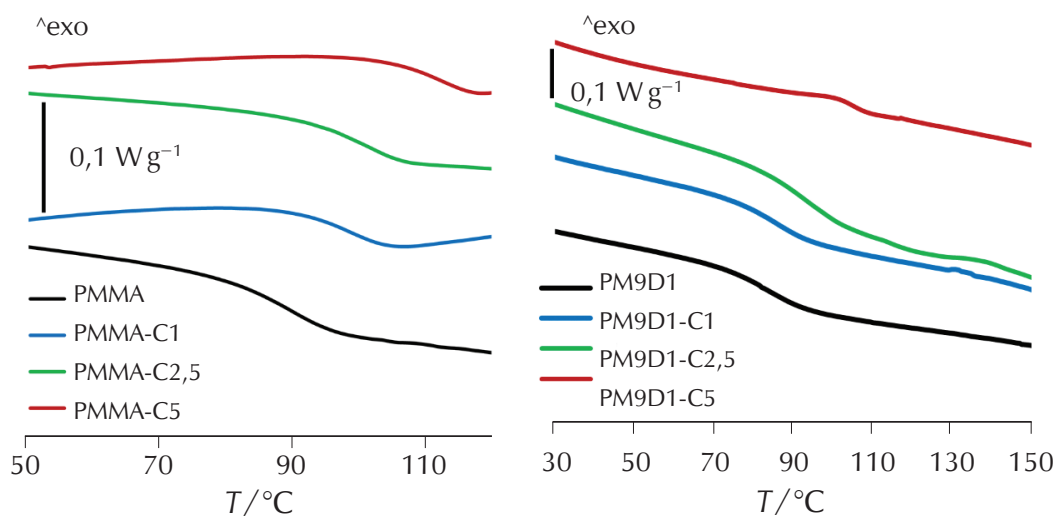

Slika 4 - Toplinski fazni prijelazi PMMA, PM9D1 i pripadajućih nanokompozita s 1, 2,5 i 5 mas. \% nanoceluloze

Fig. 4 - Thermal phase transitions of PMMA, PM9D1 and associated nanocomposites with 1, 2.5, and $5 \mathrm{wt} \%$ nanocellulose
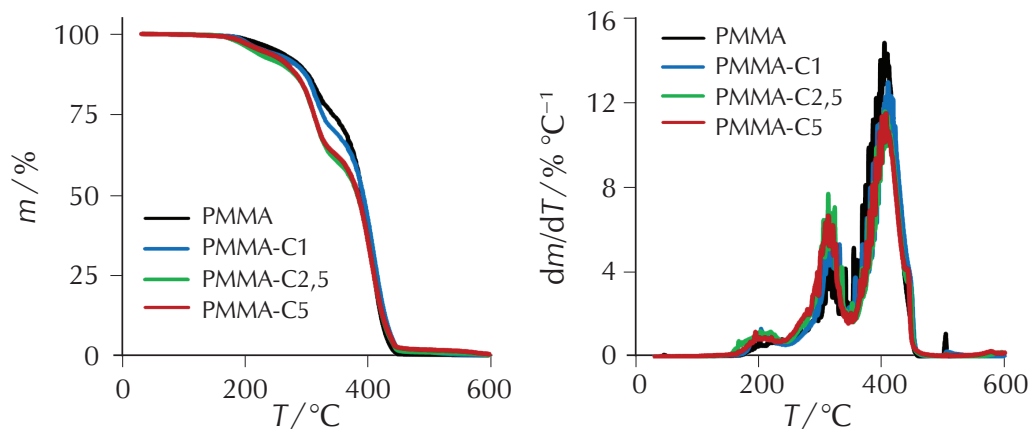

Slika 5 - Toplinska stabilnost PMMA i nanokompozita s 1, 2,5 i 5 mas. \% nanoceluloze; TG prikaz (lijevo) DTG prikaz (desno)

Fig. 5 - Thermal stability of PMMA and nanocomposites with 1, 2.5, and $5 \mathrm{wt} \%$ nanocellulose; TG view (left) DTG view (right) 
vezan je uz intenzivnu depolimerizaciju glavnog lanca. ${ }^{28}$ Iz dobivenih rezultata vidljiv je nešto veći gubitak mase $u$ prvom i drugom koraku za nanokompozite u odnosu na čisti polimer. Navedeno ukazuje na to da prilikom pripreme nanokompozita dodatak nanoceluloze u vrlo maloj mjeri pospješuje degradaciju polimerne matrice premda sama celuloza pokazuje značajniju toplinsku degradaciju tek na temperaturama većim od $300{ }^{\circ} \mathrm{C}$. Vjerojatni mehanizam jest nastajanje strukturnih defekata na polimernim lancima koji su manje toplinski postojani i uzrokuju razgradnju pri nižim temperaturama. ${ }^{29}$ Osim navedenog, dodatak nanoceluloze nema značajan utjecaj na toplinsku stabilnost polimerne matrice.

Kopolimerni sustavi PM9D1 također se raspadaju u tri koraka: prvi od 170 do $230{ }^{\circ} \mathrm{C}$, drugi u području od 250 do $340{ }^{\circ} \mathrm{C}$ te treći od 370 do $470{ }^{\circ} \mathrm{C}$ (slika 6). Dodatak dimetilaminoetil-metakrilatne komonomerne jedinice pomaknuo je temperaturu raspada trećeg koraka, depolimerizaciju glavnog lanca, za oko $+20{ }^{\circ} \mathrm{C}$. Navedenom je doprinijela interakcija između dimetilaminoetilne i metakrilatne bočne skupine, što djeluje stabilizirajuće te odgađa početak depolimerizacije na više temperature. ${ }^{30}$ Dodatak nanoceluloze kod PM9D1 sustava ne utječe na temperaturu raspada trećeg, glavnog koraka (depolimerizacija glavnog lanca). U prva dva koraka raspada u pravilu dolazi do vrlo malog pomaka prema višim temperaturama, ali općenito, dodatak nanoceluloze ne utječe značajno na toplinsku postojanost kopolimerne matrice PM9D1. u kopolimernu matricu dodatno se povećava hodrofilnost tako da je zabilježeno smanjenje kontaktnog kuta za $10^{\circ}$. Polarnost površine od osobite je važnosti za ambalažne polimerne materijale, gdje su uobičajeno potrebni ispis slika i grafičko označavanje proizvoda. ${ }^{31}$ Stoga se hidrofobni polimeri poput polietilena moraju dodatno modificirati, što ponekad zahtijeva i dodatnu opremu u postrojenjima.
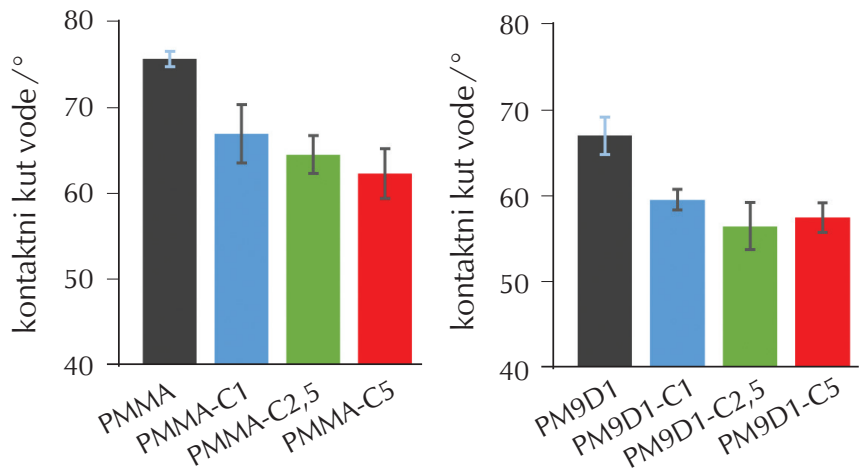

Slika 7 - Kontaktni kut vode na površini PMMA, PM9D1 i nanokompozita s 1, 2,5 i 5 mas. \% nanoceluloze

Fig. 7 - Contact angle of water on the surface of PMMA, PM9D1 and nanocomposites with 1, 2.5, and 5 wt \% nanocellulose
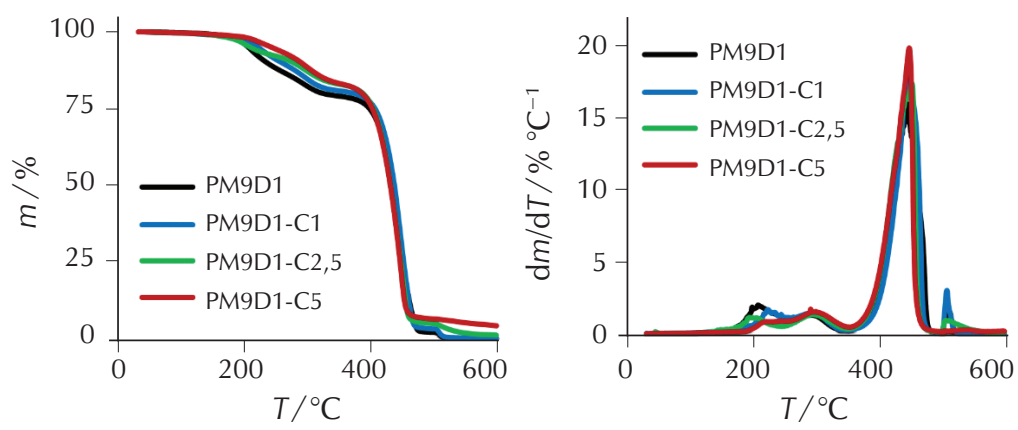

Slika 6 - Toplinska stabilnost PM9D1 i nanokompozita s 1, 2,5 i 5 mas. \% nanoceluloze; TG prikaz (lijevo), DTG prikaz (desno)

Fig. 6 - Thermal stability of PM9D1 and nanocomposites with 1, 2.5, and 5 $w t \%$ nanocellulose; TG view (left), DTG view (right)

Promjena površinskih svojstva priređenih kompozita s promjenljivim sadržajem celuloznog punila u poli(metil-metakrilatnoj) i poli(metil-metakrilat-ko-dimetilaminoetil-metakrilatnoj) matrici ispitana su mjerenjem kontaktnog kuta. Mjerenja kontaktnog kuta vode na površini uzoraka serije PMMA kompozita pokazuju trend smanjenja kontaktnog kuta s povećanjem udjela nanoceluloze, što je posljedica njezine veće polarnosti (slika 7). Nanokompoziti postaju hidrofilniji, što omogućuje bolje močenje vodom odnosno njezinu adheziju za površinu. S druge strane, uvođenje polarnije dimetilaminoetil-metakrilatne komonomerne jedinice u polimer rezultira većom hidrofilnošću matrice (kontaktni kut se smanjuje za $8^{\circ}$ ). Dodatkom nanoceluloze

\section{Zaključak}

Nanocelulozni kompozitni materijali priređeni iz otopine PMMA, postupkom koji uključuje otapanje polimera, mehaničku homogenizaciju (10 $000 \mathrm{~min}^{-1}$ ) te uklanjanje otapala vakuumskim sušenjem, postižu zadovoljavajuću raspodjelu čestica bez stvaranja aglomerata. Na SEM mikrografijama nisu uočeni aglomerati niti površinski defekti koji bi mogli ukazivati na odvajanje aglomerata prilikom pripreme uzorka za SEM analizu. Postupak pripreme ne utječe značajno na svojstva polimerne matrice, što je vidljivo iz rezultata kromatografije isključenjem po veličini koja ukazuje na pad masenog prosjeka do $5 \%$ uz blago smanjenje disperznosti. Dodatak nanoceluloznog punila pokazuje nešto izraženiji negativan utjecaj na smanjene prosjeka molekulskih masa polimerne matrice (do $13 \%$ ). Povišenje staklišta za nanokompozite koji sadrže najveći udio nanoceluloze (5 mas. \%), $21^{\circ} \mathrm{C}$ za PMMA sustav, odnosno $22^{\circ} \mathrm{C}$ za PM9D1 sustav, ukazuje na to da nanoceluloza smanjuje gibljivost polimernih lanaca zbog interakcije između punila i polimernih lanaca te steričkog ograničavanja gibljivosti. Termogravimetrijska analiza pokazuje da dodatak nanoceluloze nema značajan utjecaj na toplinsku stabilnost polimerne matrice. Smanjenje kontaktnog kuta vode na površni uzoraka pokazuje da se dodatkom nanoceluloze, kao polarnije komponente, povećava hidrofilnost kompozitnih materijala, što može imati poticajan utjecaj na njihovu primjenu. 


\section{Literatura \\ References}

1. H. P. S. Abdul Khalil, Y. Davoudpour, N. A. Sri Aprilia, A. Mustapha, S. Hossain, N. Islam, R. Dungani, Nanocellulose-Based Polymer Nanocomposite: Isolation, Characterization and Applications u V. K. Thakur (ur.) Nanocellulose Polymer Nanocomposites: Fundamentals and Applications, Scrivener Publishing LLC, 2014., str. 273-309, doi: https:// doi.org/10.1002/9781118872246.ch11

2. A. K. Rana, E. Frollini, V. K. Thakur, Cellulose nanocrystals: Pretreatments, preparation strategies, and surface functionalization, Int. J. Bio Macromol. 182 (2021) 1554-1581, doi: https://doi.org/10.1016/j.ijbiomac.2021.05.119.

3. N. Španić, V. Jambreković, S. Medved, A. Antonović, Chemical and Thermal Properties of Cellulose Acetate Prepared from White Willow (Salix alba) and Black Alder (Alnus glutinosa) as a Potential Polymeric Base of Biocomposite Materials, Chem. Biochem. Eng. Q. 29 (2015) 357-365, doi: https://doi.org/10.15255/CABEQ.2015.2176.

4. R. Blažic, K. Lenac, E. Vidović, Priprava celuloznih hidrogelova modificiranih 2-dimetilaminoetil-metakrilatom i srebrovim nanočesticama, Kem. Ind. 69 (2020) 269-279, doi: https://doi.org/10.15255/KUI.2020.013.

5. S. Iwamoto, SH. Lee, T. Endo, Relationship between aspect ratio and suspension viscosity of wood cellulose nanofibers, Polym J. 46 (2014) 73-76, doi: https://doi.org/10.1038/ pj.2013.64.

6. S. P. Bangar, W. S. Whiteside, Nano-cellulose reinforced starch bio composite films- A review on green composites, Int. J. Biol. Macromol. 185 (2021) 849-860, doi: https://doi. org/10.1016/j.ijbiomac.2021.07.017.

7. K. Sakakibara, H. Yano i Y. Tsujii, Surface Engineering of Cellulose Nanofiber by Adsorption of Diblock Copolymer Dispersant for Green Nanocomposite Materials, ACS Appl. Mater. Interfaces 8 (2016) 24893-24900, doi: https://doi. org/10.1021/acsami.6b07769.

8. L. Heux, G. Chauve, C. Bonini, Nonflocculating and chiral-nematic self-ordering of cellulose microcrystals suspensions in nonpolar solvents, Langmuir 16 (2000) 8210-8212, doi: https://doi.org/10.1021/la9913957.

9. J. Shojaeiarani, D. S. Bajwa, S. Chanda, Cellulose nanocrystal based composites: A review, Composites Part C: Open Access 5 (2021) 100164, doi: https://doi.org/10.1016/j. jcomc.2021.100164.

10. URL: https://www.celluloselab.com/our-products/ (pristupljeno: 20. 7. 2021.).

11. V. Favier, H. Chanzy, J. Y. Cavaille, Polymer nanocomposites reinforced by cellulose whiskers, Macromolecules 28 (1995) 6365-6367, doi: https://doi.org/10.1021/ma00122a053.

12. V. Favier, G. R. Canova, J. Y. Cavaille, H. Chanzy, A. Dufresne, C. Gauthier, Nanocomposite materials from latex and cellulose whiskers, Polym. Adv. Technol. 6 (1995) 351-355, doi: https://doi.org/10.1002/pat.1995.220060514.

13. A. Dufresne, D. Dupeyre, M. R. Vignon, Cellulose microfibrils from potato tuber cells: processing and characterization of starch-cellulose microfibril composites, J. Appl. Polym. Sci. 76 (2000) 2080-2092, doi: https://doi.org/10.1002/(SICI)10974628(20000628)76:14<2080::AID-APP12>3.0.CO;2-U.

14. A. N. Nakagaito, H. Yano, The effect of morphological changes from pulp fiber towards nano-scale fibrillated cellulose on the mechanical properties of high-strength plant fiber based composites, Appl. Phys. A-Mater. Sci. Process 78 (2004) 547-552, doi: https://doi.org/10.1007/s00339-003-2453-5.

15. T. Zimmermann, E. Pöhler, T. Geiger, Cellulose fibrils for polymer reinforcement, Adv. Eng. Mater. 6 (2004) 754-761, doi: https://doi.org/10.1002/adem.200400097.
16. S. Fujisawa, E. Togawa, S. Kimura, Large specific surface area and rigid network of nanocellulose govern the thermal stability of polymers: Mechanisms of enhanced thermomechanical properties for nanocellulose/PMMA nanocomposite, Mater. Today Commun. 16 (2018) 105-110, doi: https://doi. org/10.1016/j.mtcomm.2018.05.002.

17. M. J. Cho, B. D. Park, Tensile and thermal properties of nanocellulose-reinforced poly(vinyl alcohol) nanocomposites, J. Ind. Eng. Chem. 17 (2011) 36-40, doi: https://doi. org/10.1016/j.jiec.2010.10.006.

18. S. Virtanen, J. Vartianenb, H. Setäläb, T. Tammelinb, S. Vuotic, Modified nanofibrillated cellulose-polyvinyl alcohol films with improved mechanical performance, RSC Adv. 4 (2014) 11343-11350, doi: https://doi.org/10.1039/C3RA46287K.

19. A. J. Menezes, G. Siqueira, A. A. S. Curvelo, A. Dufresne, Extrusion and characterization of functionalized cellulose whiskers reinforced polyethylene nanocomposites, Polymer 50 (2009) 4552-4563, doi: https://doi.org/10.1016/j.polymer.2009.07.038.

20. M. Grunert, W. T. Winter, Nanocomposites of Cellulose Acetate Butyrate Reinforced with Cellulose Nanocrystals, J. Polym. Environ. 10 (2002) 27-30, doi: https://doi. org/10.1023/A:1021065905986.

21. K. Mackenzie, A. E. Jemmett, Polymer shear stability, Wear 17 (1971) 389-398, doi: https://doi.org/10.1016/00431648(71)90045-7.

22. C. Capone, L. Di Landro, F. Inzoli, M. Penco, L. Sartore, Thermal and mechanical degradation during polymer extrusion processing, Polym. Eng. Sci. 47 (11) (2007) 1813-1819, doi: https://doi.org/10.1002/pen.20882.

23. T. McNally, P. Pötschke, Polymer-Carbon Nanotube Composites: Preparation, Properties and Applications, Woodhead Publishing, 2011.

24. K. Kraguljac, E. Vidović, I. Šoljić Jerbić, A.Jukić, A Chromatographic study of shear stability of poly(styrene-co-alkyl methacrylate) viscosity modifier for lubricating oils, Pet. Sci. Technol. 33 (2015) 374-380, doi: https://doi.org/10.1080/1 0916466.2014 .988872$.

25. S. W. Kuo, Hydrogen bonding in polymer blends, J. Polym. Res. 15 (2008) 459-486, doi: https://doi.org/10.1007/ s10965-008-9192-4.

26. M. Jonoobi, Y. Aitomäki, A. P. Mathew, K. Oksman, Thermoplastic polymer impregnation of cellulose nanofibre networks: Morphology, mechanical and optical properties, Composites: Part A 58 (2013) 30-35, doi: https://doi. org/10.1016/j.compositesa.2013.11.010.

27. E. E. Kiziltas, A. Kiziltas, S. C. Bollin, D. J. Gardner, Preparation and characterization of transparent PMMA-cellulose-based nanocomposites, Carbohydr. Polym. 127 (2015) 381-389, doi: https://doi.org/10.1016/j.carbpol.2015.03.029.

28. T. Kashiwagi, T. A. Inaba, J. E. Brown, K. Hatada, T. Kitayama, E. Masuda, Effects of weak linkages on the thermal and oxidative degradation of poly(methyl methacrylates), Macromolecules 19 (1986) 2160-2168, doi: https://doi. org/10.1021/ma00162a010.

29. D. Ciolacu, V. I. Popa, On the Thermal Degradation of Cellulose Allomorphs, Cellul. Chem. Technol. 40 (6) (2006) 445-449.

30. S. G. Roy, K. Bauri, S. Pal, A. Goswami, G. Madras, P. De, Synthesis, characterization and thermal degradation of dual temperature- and $\mathrm{pH}$-sensitive RAFT-made copolymers of $N, N$-(dimethylamino)ethyl methacrylate and methyl methacrylate, Polym. Int. 62 (2013) 463-473, doi: https://doi. org/10.1002/pi.4335.

31. C. Aydemir, B. N. Altay, M. Akyol, Surface analysis of polymer films for wettability and ink adhesion, Color Res. Appl. 46 (2020) 489-499, doi: https://doi.org/10.1002/col.22579. 


\title{
SUMMARY
}

\section{Preparation and Characterization of Poly(methyl methacrylate) Composites with Nanocellulose}

\author{
Kristijan Mrkalj, Fabio Faraguna, Elvira Vidović, and Ante Jukić*
}

The composite materials based on poly(methyl methacrylate) and poly(methyl methacrylate-co-dimethylaminoethyl methacrylate) with nanocellulose in the proportion of $1,2.5$, and $5 \mathrm{wt} \%$ were prepared. The homogeneous distribution of nanofillers in the polymer matrix was obtained from the solution by the ex situ method. Exclusion size chromatography showed that the strong shear force applied during homogenization caused the largest polymer molecules to crack and thus slightly reduce the average molecular weight of the polymer matrix. Higher glass transition temperatures of composites compared to pure polymer matrices and their increase with increasing filler content, confirm the homogeneity of distribution and compatibility of nanocellulose with the investigated methacrylate matrices. The addition of nanocellulose increases the hydrophilicity of materials, which facilitates printing and may favor their use as packaging materials.

\section{Keywords}

Poly(methyl methacrylate), nanocellulose, DSC, SEC, solution mixing

Faculty of Chemical Engineering and Technology

Original scientific paper

University of Zagreb

Trg Marka Marulića19

Received July 22, 2021

10000 Zagreb, Croatia 